\title{
Chemical burn caused by high-concentration hydrofluoric acid: a case that followed a lethal course
}

Takayuki Onohara ${ }^{1}$, Mayumi Komine ${ }^{2 *}$, Yuya Yoshidomi ${ }^{1}$, Kaori Amari ${ }^{1}$, Ryo Fujita ${ }^{1}$, Yasushi Matsumoto ${ }^{1}$, Takashi Koyama ${ }^{1}$, Mika Koga $^{3}$, Shinji Mitsumizo ${ }^{3}$, Yoshiyasu Satake ${ }^{4}$, Kazuyuki Masumoto ${ }^{4}$, Taiki Matsunaga ${ }^{5}$, Takao Mae and Naohiro Fujita $^{1}$

${ }^{1}$ Emergency and Critical Care Center, Saga-ken Medical Centre Koseikan, Saga, Japan

${ }^{2}$ Department of Dermatology, Jichi Medical University, Tochigi, Japan

${ }^{3}$ Intensive Care Unit, Saga-ken Medical Centre Koseikan, Saga, Japan

${ }^{4}$ Plastic Surgery, Saga-ken Medical Centre Koseikan, Saga, Japan

${ }^{5}$ Orthopedics, Saga-ken Medical Centre Koseikan, Saga, Japan

\begin{abstract}
Chemical burns from Hydrofluoric Acid (HFA) are poorly recognized, even though we sometimes encounter patients affected by these burns. HFA can cause lethal arrhythmia due to hypocalcemia and hypomagnesemia, particularly in cases of high-concentration HFA exposure. A 57-year-old man received lower body injuries from splashes of $50 \% \mathrm{HFA}$ solution by an accident. He was transferred to our hospital by a helicopter emergency medical service (Doctor Heli). $10 \mathrm{~mL}$ of calcium gluconate solution ( $8.5 \%$ calcium gluconate) had been already administered before arrival to the emergency room. However, hypocalcemia was prolonged, fatal arrhythmia appeared, and we started the continuous administration of calcium gluconate. We amputated his leg in order to prevent systemic spreading of HFA. Further, we administered a massive transfusion of saline with catecholamine for the treatment of shock. However, the patient died after 7 hrs. In many reported cases of exposure to high-concentration HFA, death from fatal arrhythmia occurred within $1 \mathrm{hr}$. Our patient was able to survive for 7 hrs, perhaps because of the early and intensive administration of calcium formulation and intensive care. This case serves as a warning to persons handling HFA, emergency physicians and dermatologists, who should recognize the corrosive nature and the potential risks of HFA to avoid tragic outcomes.
\end{abstract}

\section{Introduction}

Hydrofluoric acid (HFA) is widely used in both domestic and industrial materials for cleaning glass, metal, and brick. HFA can cause intractable arrhythmia induced by hypocalcemia, hypomagnesemia, and hyperkalemia, resulting in death. Despite its hazardous nature, the risk of HFA burns is not well recognized, even to those who handle this material.

We experienced a case of chemical burns involving 50\% HFA exposure, which resulted in third-degree burns over $30 \%$ of the body. The case followed a lethal course despite the rapid and continuous administration of calcium with intensive care, which allowed the patient to survive for $7 \mathrm{hrs}$.

\section{Case report}

Accidental leakage of hydrofluoric acid (HFA) from a tank occurred at 8:45 in the morning. No individuals were close to the tank when the leakage occurred. However, a 57-year-old man (the patient) entered the area at 9:35 in order to examine the state of the accident. He was wearing goggles, a gas mask, and long boots. Immediately after he entered the area, the tank exploded. HFA splashed on his lower body, and he immediately washed himself with water. After the injury, his lower body was continuously washed with running water for 20 min by his colleagues until an ambulance arrived. The patient started to complain of dyspnea and chest discomfort, and his general condition gradually worsened while waiting for the ambulance. Emergency services arrived on the scene and requested a helicopter emergency medical service (Doctor Heli), which transferred the patient to our hospital.
On arrival, his level of consciousness was Glasgow coma scale E1VTM1. Midazolam ( $2 \mathrm{mg}$ ), vecuronium ( $8 \mathrm{mg}$ ), and buprenorphine $(0.2 \mathrm{mg})$ had already been administered by the emergency service personnel on the helicopter. His body temperature was $37.7^{\circ} \mathrm{C}$, his heart rate was 105 per min, his blood pressure was $125 / 95 \mathrm{mmHg}$, and his $\mathrm{SpO}_{2}$ was $100 \%$ with $\mathrm{FiO}_{2} 1.0$ with tracheal intubation.

Both of his lower limbs were extensively involved. There were extensive reddened lesions with ulcer and necrotic tissue extending from both of his thighs to his lower legs (Figure 1). Occasional whitish necrotic lesions were present, especially on his knees and the lower part of his right leg to the dorsum of his right foot (Figure 2). We estimated that the burn was third degree, $30 \%$.

Blood chemistry revealed that he had hypocalcemia $(2.2 \mathrm{mg} /$ $\mathrm{dL})$, hypomagnesemia $(0.8 \mathrm{mg} / \mathrm{dL})$, and hyperkalemia $(5.8 \mathrm{mEq} / \mathrm{L})$. Coagulation dysfunction was also noted (D-dimer, $35.2 \mu \mathrm{g} / \mathrm{mL}$ ). Renal dysfunction (creatinin $1.25 \mathrm{mg} / \mathrm{dL}$ ) and metabolic acidosis ( $\mathrm{pH}$ 6.997, base excess-13.5 $\mathrm{mmol} / \mathrm{L}$ ) were present.

Correspondence to: Mayumi Komine, M.D., Ph.D., Department of Dermatology, Jichi Medical University, 3311-1 Yakushiji, Shimotsuke, Tochigi, 329-0498, Japan, Tel: +81-28558-7360; Fax: +81-285-44-4857; E-mail: mkomine12@jichi.ac.jp

Key words: arrhythmia, calcium gluconate, chemical burn, hydrofluoric acid, hypocalcemia

Received: October 18, 2015; Accepted: November 20, 2015; Published: November 24, 2015 


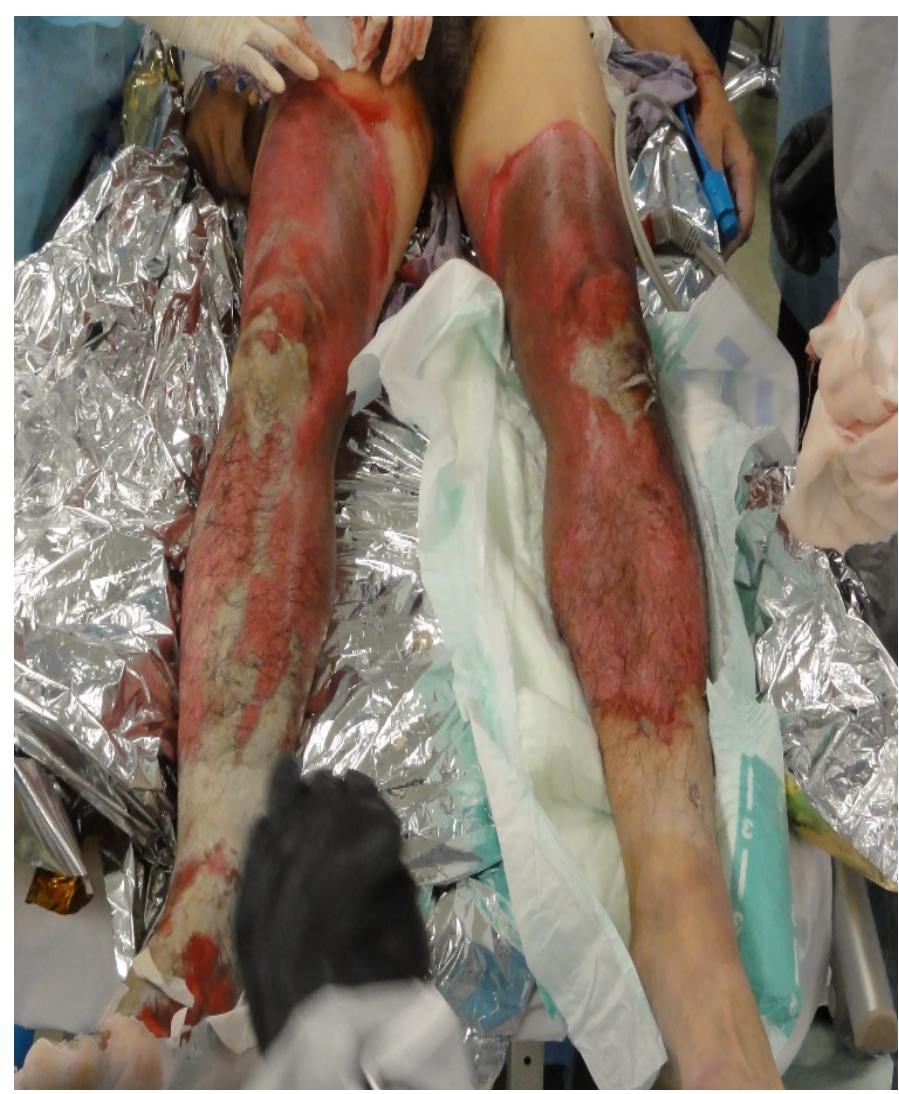

Figure 1. The clinical presentation of the lower legs.
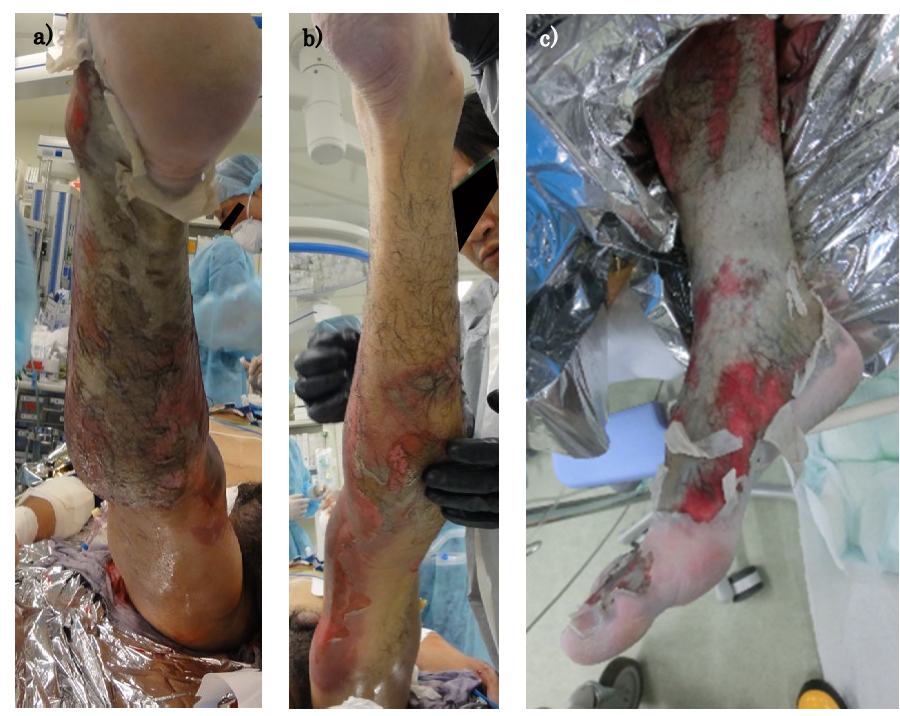

Figure 2. Clinical presentation of (a) the right leg, dorsal side, (b) the left leg, dorsal side (c) and the right ankle.

$10 \mathrm{~mL}$ of calcium gluconate solution (8.5\% calcium gluconate) had already been administered before arrival to the emergency room. Because an electrocardiogram showed a wide QRS that suggested hypocalcemia, we administered calcium gluconate again; however, pulseless ventricular tachycardia occurred. Defibrillation at $150 \mathrm{~J}$ was immediately performed and the pulse pressure was restored. Although we frequently administered calcium gluconate, hypocalcemia was prolonged, and we started the continuous administration of calcium gluconate $(50 \mathrm{~mL} / \mathrm{h}, 8.5 \%$ solution). In order to correct shock and metabolic acidosis, we started the administration of catecholamine, the vasopressor, and massive transfusion with normal saline. With the objective of preventing HFA flowing back into systemic circulation, we performed an amputation of the right lower leg, as well as extensive skin debridement of left leg. During the operation, calcium chloride, magnesium sulfate, and catecholamine were continuously administered; however, ameliorating the shock state was extremely difficult.

After ventricular fibrillation followed by immediate cardiopulmonary resuscitation, the patient had massive bleeding from the wound to the right thigh. Hemostasis was difficult. Because of the progression of disseminated intravascular coagulation with progressive organ damage and pulseless electronic activity, we gave up resuscitation at $16: 20$.

\section{Discussion}

Hydrogen fluoride is a gas at $25^{\circ} \mathrm{C}$, and its aqueous solution is called hydrofluoric acid (HFA). HFA is widely used in both domestic and industrial applications, often for cleansing electronic products, glass, ceramics, and metals. HFA is an inorganic weak acid with strong tissue corrosiveness. It produces progressive and serious tissue damage with severe systemic effects. The degree of tissue damage is dependent on the concentration and the involved area [1]. Tissue damage by HFA is caused via two distinct mechanisms. First, damage caused by hydrogen ions produces corrosive burns. Second, fluoride ions have a highly lipophilic nature and penetrate tissues deeply, leading to tissue necrosis [1]. The liberated fluorine ions enter the cells and bind calcium and magnesium, causing hypocalcemia and hypomagnesemia. The formation of calcium fluoride $\left(\mathrm{CaF}_{2}\right)$ crystals causes a fall in the serum calcium concentration, resulting in pain and cramping. The potassium channel is forced open by calcium-dependent inhibition on $\mathrm{Na}^{+} / \mathrm{K}^{+}$ATPase, which causes hyperkalemia. Myocardial adenylate cyclase is activated by fluoride ions, which increases cAMP and stimulates the myocardium, inducing refractory and fatal arrhythmia [2].

Ohtani et al. reported an autopsied case with HFA burns. In their case, histopathological study of the skin demonstrated severe dermal damage with the disappearance of blood vessels and elastic fibers, as well as less-severe damage to the epidermis. They mention that the pathological changes to the skin progressed extremely rapid, even though the HFA had immediately been rinsed off [3].

A review of several journals of emergency medicine [2,4,5] showed that patients exposed to high-concentration HFA died from fatal arrhythmia within $1 \mathrm{hr}$ in many reported cases. In the present case, the patient's general condition quickly worsened after the injury. However, early decontamination and rapid transport of the patients with rapid initiation of calcium administration might have led to his $7 \mathrm{hrs}$ period of survival of the injury. Several cases with milder exposures have been reported from dermatology departments [6-8]. The most common presentation of HFA burns is for the group of patients exposed to weak solutions of approximately $3 \%$ HFA, such as are found in metal cleansers. In these cases, HFA burns can take many hours to produce symptoms, and patients often become aware of severe pain in the middle of the night following exposure during the day [1]. It is not very well known that 1 ) exposure of as little as $1 \%$ of the total body surface area to more than 50\% HFA solution and 2) exposure of more than $5 \%$ of the total body surface area to HFA of any concentration present high risks of hypocalcemia, which could cause life-threatening 
situations [9]. It is extremely important to be aware that, even with a small area of exposure, emergency care could be needed, depending on the concentration of HFA.

Exposure to high concentrations of HFA is potentially lethal, but the potential risks are not sufficiently recognized [10]. In our case, even though the patient was an employee of the company handling HFA, the patient's actions were imprudent because he approached the leaking tank that contained HFA without sufficient protective clothing. It is necessary to educate both employees and employers about the corrosive nature of HFA and the risks of exposure to HFA. Further, it is necessary to establish an effective emergency manual to prevent future industry accidents resembling this case.

\section{Acknowledgements}

Consultations for the publication of this case were provided by Mayumi Komine (Department of Dermatology, Jichi Medical University).

\section{References}

1. Hatzifotis M, Williams A, Muller M, Pegg S (2004) Hydrofluoric acid burns. Burns 30: 156-159.
2. McKee D, Thoma A, Bailey K, Fish J (2014) A review of hydrofluoric acid burn management. Plast Surg 22: 95-98. [Crossref]

3. Ohtani M, Nishida N, Chiba T, Muto H, Yoshida N (2007) Pathological demonstration of rapid involvement into the subcutaneous tissue in a case of fatal hydrofluoric acid burns. Forens Sci Int 167: 49-52. [Crossref]

4. Kirkpatrick J, Burd D (1995) Hydrofluoric acid burns: a review. Burns 21: 483-493. [Crossref]

5. Upfal M, Doylw C (1990) Medical management of hydrofluoric acid exposure. J Occup Med 32: 726-731. [Crossref]

6. Ohata U, Hara H, Suzuki H (2005) 7 cases of hydrofluoric acid burn in which calcium gluconate was effective for relief of severe pain. Contact Dermatitis 53: 133-137. [Crossref]

7. Fujimoto K, Yasuhara N, Kawarada H, Kosaka S, Kawana S (2002) Burns caused by dilute hydrofluoric acid in the bleach. J Nippon Med Sch 69: 180-184. [Crossref]

8. Piraccini BM, Rech G, Pazzaglia M, Tullo S, Iorizzo M, et al. (2005) Peri- and subungual burns caused by hydrofluoric acid. Contact Dermatitis 52: 230-232. [Crossref]

9. Greco RJ, Hartford CE, Haith Jr LR, Pattin ML (1988) Hydrofluoric acid-induced hypocalcemia. J Trauma 28: 1593-1596. [Crossref]

10. Yamamoto O, Yasuda H, Izu K, Nishio D, Asahi M (2000) Occupationally induced hydrofluoric acid burns. An analysis of 9 patients from the aspect of occupational health. JUOEH 22: 167-175. [Crossref]

Copyright: (C2015 Onohara T. This is an open-access article distributed under the terms of the Creative Commons Attribution License, which permits unrestricted use, distribution, and reproduction in any medium, provided the original author and source are credited. 